Jul 13th, 10:50 AM - 11:10 AM

\title{
Comparison of Parametric and Non-Parametric Disaggregation Models for the Top-Down Generation of Water Demand Time Series
}

\section{S. Alvisi}

University of Ferrara, stefano.alvisi@unife.it

N. Ansaloni

TeaAcque Srl, nicola.ansaloni@teaspa.it

M. Franchini

University of Ferrara, marco.franchini@unife.it

Follow this and additional works at: https://scholarsarchive.byu.edu/iemssconference

Part of the Civil Engineering Commons, Data Storage Systems Commons, Environmental Engineering Commons, Hydraulic Engineering Commons, and the Other Civil and Environmental Engineering Commons

Alvisi, S.; Ansaloni, N.; and Franchini, M., "Comparison of Parametric and Non-Parametric Disaggregation Models for the Top-Down Generation of Water Demand Time Series" (2016). International Congress on Environmental Modelling and Software. 45.

https://scholarsarchive.byu.edu/iemssconference/2016/Stream-C/45

This Event is brought to you for free and open access by the Civil and Environmental Engineering at BYU ScholarsArchive. It has been accepted for inclusion in International Congress on Environmental Modelling and Software by an authorized administrator of BYU ScholarsArchive. For more information, please contact scholarsarchive@byu.edu, ellen_amatangelo@byu.edu. 


\title{
Comparison of Parametric and Non-Parametric Disaggregation Models for the Top-Down Generation of Water Demand Time Series
}

\author{
Alvisi S. ${ }^{\mathrm{a}}$, Ansaloni N. ${ }^{\mathrm{b}}$ and Franchini $\mathrm{M}^{\mathrm{a}}$ \\ ${ }^{a}$ Department of Engineering, University of Ferrara, Via Saragat 1, 44122 Ferrara, ITALY \\ ${ }^{b}$ TeaAcque Srl, Via Taliercio 3, 46100 Mantova, ITALY \\ e-mails: stefano.alvisi@unife.it; nicola.ansaloni@teaspa.it; marco.franchini@unife.it
}

\begin{abstract}
This study presents a "top-down" procedure for generating synthetic time series of hourly nodal water demands from time series of the total water demands in the area that includes the nodes considered, based on the application of disaggregation models already presented in the literature in the field of hydrology. More specifically, a parametric and a nonparametric disaggregation model are compared to assess their performance in reproducing, on a nodal level, the main statistics of the time series of historically observed water demands. Moreover, with regard to the nonparametric model, two variants of the original formulation are proposed with the aim of improving the ability to reproduce the lag-1 temporal correlations of the water demand time series generated by disaggregation.

The proposed procedures were evaluated with reference to a case study based on a time series of the water demands of 21 users of the water distribution system of the town of Milford (Ohio). The results obtained showed that both the parametric and nonparametric models enable water demand time series to be generated which are statistically similar to the time series observed ; in particular, the comparison between the two approaches revealed that the nonparametric model can better reproduce the skewness of the probability distributions of the nodal demands, whilst the parametric model better reproduces the temporal correlations at lag 1 . The modifications introduced to the original formulation of the nonparametric model serve to improve the reproduction of temporal correlations at lag 1 , though in certain cases they produce distortions in some of the statistics. In general, the results obtained demonstrate that the proposed procedures represent a valid tool for generating synthetic series of nodal water demands from a spatially aggregated time series using a top-down approach.
\end{abstract}

Keywords: Water demands; time series; disaggregation. 